\title{
STRUCTURAL ANALYSIS OF TUNGSTEN BASED HYDROGEN STORAGE MATERIALS
}

Carly C. Carter ${ }^{\mathrm{b}}$, Brandon R. Allen ${ }^{\mathrm{a}}$, Daniel V. Bui ${ }^{a}$, Delroy A. Daley ${ }^{\mathrm{a}}$, Christopher M. Holinej ${ }^{\mathrm{a}}$, Julia M. Goncalves ${ }^{\mathrm{a}}$,

Sherlin Lira ${ }^{a}$, David E. Muniza, Alanis I. Santiago ${ }^{a}$, Nihmal Sukran ${ }^{a}$,Thomas R. Cundarib* and Muhammed Yousufuddina*

${ }^{a}$ University of North Texas at Dallas, Life and Health Sciences Department

bUniversity of North Texas, Department of Chemistry

\begin{abstract}
We present here the synthesis, crystal structures, and DFT calculations of ungsten (IV) and We present here the synthesis, crystal structures, and DFT calculations of tungsten (IV) and
tungsten (VI) phosphino polyhydrides. We have used high quality X-ray diffraction at low temperature to assist in locating, for the first time, the hydrides in these complexes. The polyhydrides each contain four phosphine ligands with the general formula $\mathrm{P}\left(\mathrm{RPh}_{2}\right)$ (where $\mathrm{R}=\mathrm{Me}$ or Et) making very intriguing eight and nine-coordinate complexes. The eightcoordinate complexes [tungsten (IV)] resemble a slightly distorted dodecehedron while the Rine DFT geometries showing the position of the hydrides for all three compounds that were crystallographically characterized have also been calculated. The combination of our results indicate that these compounds are best described as classical metal hydride.
\end{abstract}

Synthesis of the Tungsten Tetrahydride Compound

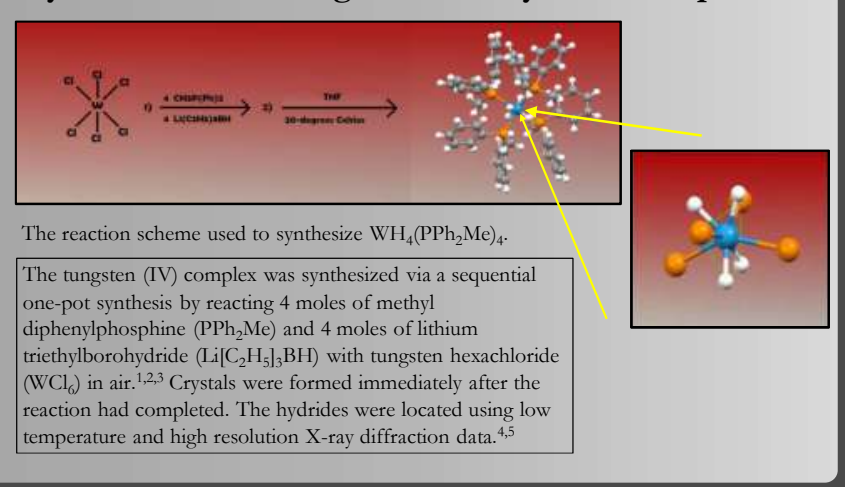

Other Tungsten Polyhydrides

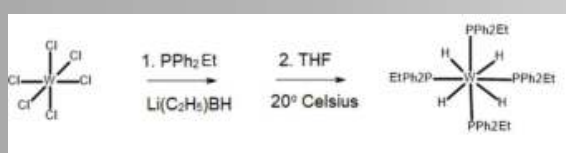

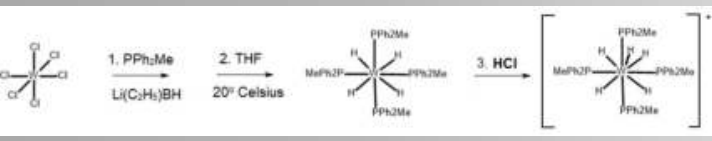

Other tungsten polyhydrides were also synthesized. $\mathrm{WH}_{4}\left(\mathrm{PPh}_{2} \mathrm{Et}\right)_{4}$ was synthesized using a similar method as described above but instead the $\mathrm{PPh}_{2} \mathrm{Et}$ was used as the stabilizing ligand. $\left[\mathrm{WH}_{5}\left(\mathrm{PPh}_{2} \mathrm{Me}_{4}\right)_{4}^{+}\right.$was synthesized by adding $\mathrm{HCl}$ to $\mathrm{WH}_{4}\left(\mathrm{PPh}_{2} \mathrm{Me}_{4}\right.$ to form the corresponding salt. For $\mathrm{WH}_{4}\left(\mathrm{PPh}_{2} \mathrm{Et}\right)_{4}$ crystals formed immediately. For $\left[\mathrm{WH}_{5}\left(\mathrm{PPh}_{2} \mathrm{Me}\right)\right.$
crystals were formed after storing the reaction vessel in $2-20^{\circ} \mathrm{C}$ freezer for one week

Our attempts to synthesize $\mathrm{WH}_{4}\left[\mathrm{P}\left(\mathrm{Me} e_{2} \mathrm{Ph}\right)\right]_{4}$ the methods presented here were not successful. $\mathrm{P}\left(\mathrm{Me}_{2} \mathrm{Ph}\right)$ is very air-sensitive and we believe that this ligand may have decomposed in our attempt to manipulate it in air. It should also be noted that our attempts to synthesize $\mathrm{WH}_{4}\left(\mathrm{PPh}_{3}\right)_{4}$ using a similar method to the formation of, what we presume to be, $\mathrm{W}\left(\mathrm{PPh}_{3}\right)_{3}$ as no hydrogen atoms could be found around the metal via preliminary crystallographic analysis. However this compound was only investigated using

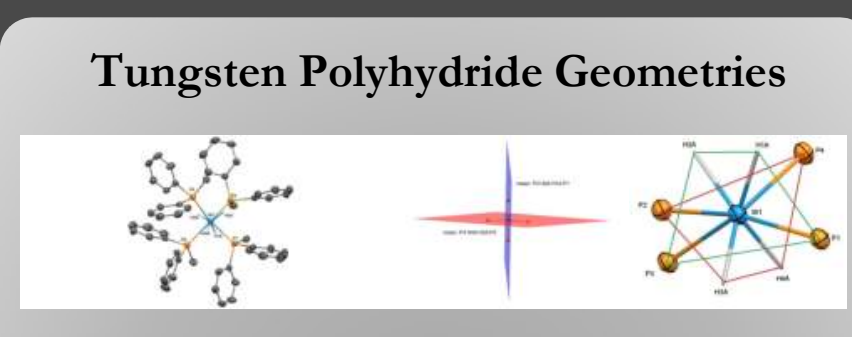

The X-ray structure of $\mathrm{WH}_{4}\left(\mathrm{PPh}_{2} \mathrm{Me}\right)_{4}$ (left) with the core represented in the middle and right.

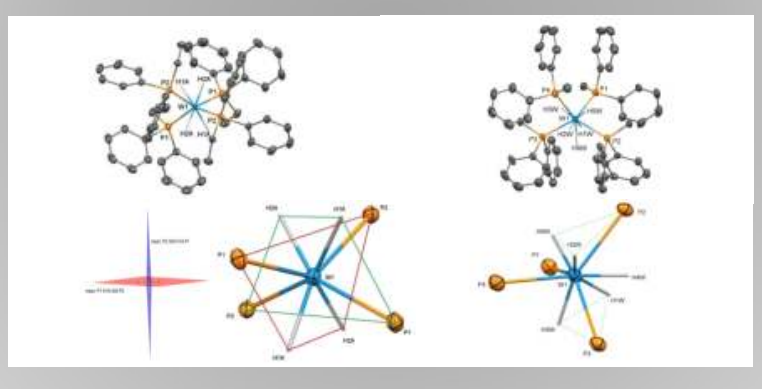

X-ray structure of to $\mathrm{WH}_{4}\left(\mathrm{PPh}_{2} \mathrm{Et}\right)_{4}$ (top left) and $\left[\mathrm{WH}_{5}\left(\mathrm{PPh}_{2} \mathrm{Me}_{4}\right]^{+}\right.$(top right). The core $\mathrm{X}$-ray structure of to $\mathrm{WH}_{4}\left(\mathrm{PPh}_{2} \mathrm{Et}\right)_{4}$ (top left) and $\left[\mathrm{WH}_{5}\left(\mathrm{PPh}_{2} \mathrm{Me}\right)_{4}\right]^{+}$(top right). The corct
of to $\mathrm{WH}_{4}\left(\mathrm{PPh}_{2} \mathrm{Et}\right)_{4}$ is shown on the bottom left and the core of $\left[\mathrm{WH}_{5}\left(\mathrm{PPh}_{2} \mathrm{Me}_{4}\right)^{+}\right.$is shown on the bottom right.

Dodecahedron Geometries for Tetrahydrides

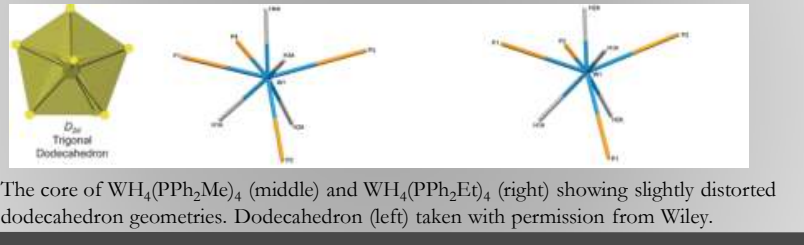

Optimized Structures from DFT Calculations

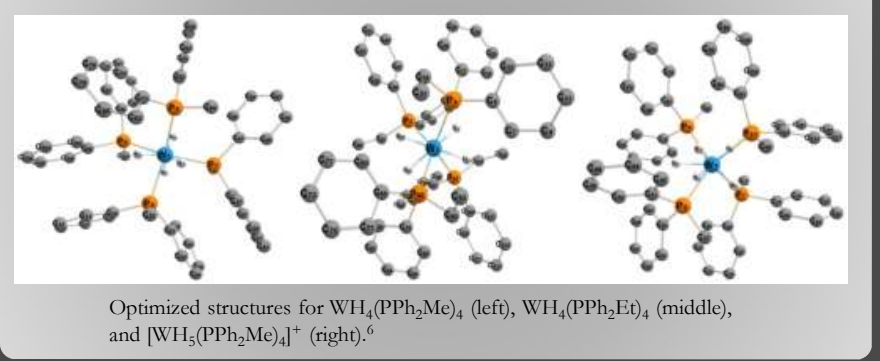

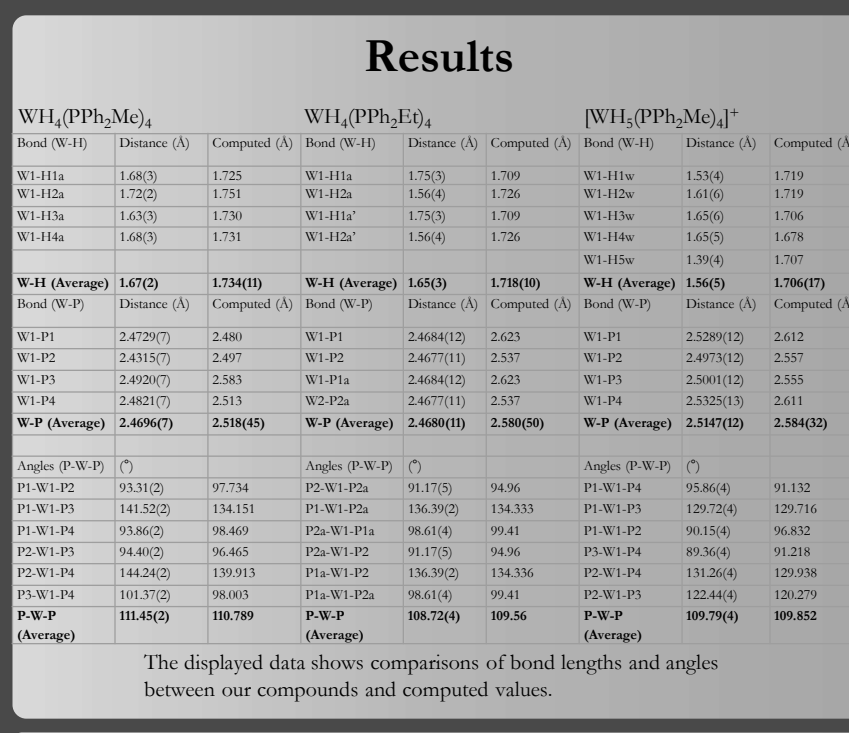

\section{Conclusion}

In summary, our group has successfully synthesized and determined the $\mathrm{X}$-ray structure (complete with hydrogen atoms surrounding the metal) of three tungsten phosphino

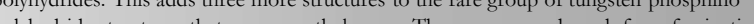
phes for all three compounds have also been computed with the lowest energy demonstrating chssical metal hydrides. It is hoped that future studies into transition metal polyhydrides will contribute to the further understanding of the metal-hydrogen interaction. This may

\section{References}

[1] "Molybdenum and Tunosten Phosphine Polyhydrides" by G. G. Hlatky and R. H. Crabtree, Inorganic Synthesis Volume 22, Wiley (1990) 8-10;

[2] "Improved synthesis of some molybdenum and tungsten tetrahydrides" by R. H. Chat 21 (1982) 1273-1275;

[3] "The reaction of tetrahydridotetrakis(methyldiphenylphosphine)-molybdenum(IV) and tungsten(IV) with

[4] X-ray diffraction Data was collected at the University of Texas at Arlington

[5] (a) Bruker-AXS (2000); (b) Bruker-AXS (2006); (c) Bruker-AXS (2000); (d) Bruker-AXS (2006); (e) G. M. Sheldrick, Acta Cryst. C, 71 (2015) 3-8

[6] Gaussian 16, RevisionA.03, Frisch, M. J. et al. Gaussian, Inc., Wallingford CT, (2016) 